\title{
Corrugate Fiber Reinforced Plastic Sheet in Repairing Tunnel Linings
}

\author{
Takashi Hara
}

Department of Civil Engineering and Architecture, National Institute of Technology, Tokuyama College, Shunan 745-8585, Japan

\begin{abstract}
This paper represented the numerical analysis of the FRP (fiber reinforced plastics) tunnel lining which was used for maintaining the old tunnel. An old tunnel covered with a concrete is prone to deteriorate due to an aging effect and a water penetration. In the rehabilitation of lining concrete, a steel plate and FRP or carbon sheet have been applied. However, these sheets show small flexural rigidity and do not flow out the penetrating water. In this paper, FRP corrugate sheet was proposed. The tunnel lining was made by FRP corrugate sheet that supported the lining concrete in the tunnel and flowed the water and the moisture swept on the tunnel surface. The FRP corrugate sheet was supported by the anchor bolts. In numerical analyses, the finite element degenerate shell was adopted to represent the FRP sheet behavior. Assuming that the concrete liner at the top was fallen down, the peeled concrete was applied as the load. From the numerical analysis, the effectiveness of the FRP corrugate sheet was confirmed.
\end{abstract}

Key words: FRP, tunnel, lining, corrugate sheet, FEM, rehabilitation.

\section{Introduction}

Tunnels have been used for a road, a railway, a sewage line and industrial usage. In case of the tunnel with large cross section, the concrete splayed after digging the rock. Then, the concrete is filled between the splayed concrete and the tunnel form, and the tunnel has been stiffened by the concrete lining (Fig. 1). However, in case of old tunnel, the concrete had been poured from top and compacted with vibrator to distribute them into an vacant space between them before a self-consolidating concrete was developed [1]. Therefore, the materials were separated during the vibration. At the crown of the tunnel, a poor concrete has been obtained because of the breezing of a concrete. Therefore, the concrete at the arch crown was low strength and was prone to peeling and cracking due to the alternative load during the vibration of the vehicles. Several accidents by a concrete cracks and a concrete block falling have been reported [2]. Especially, in the cold region, the water

Corresponding author: Takashi Hara, Dr., professor, research fields: concrete shell structure with numerical and experimental analyses. E-mail: t-hara@tokuyama.ac.jp. penetrated into the cracks of concrete and cracks opened and closed repeatedly due to the freezing of the water and the melting of the ice.

Therefore, to maintain such a concrete lining, the cover sheet should be placed inside the tunnel. The cover sheet has to be placed not only to support the falling concrete blocks but also to flow the moisture or the water. In the rehabilitation of lining concrete, a steel plate and FRP (fiber reinforced plastics) or carbon sheet have been applied [3]. However, these sheets show small flexural rigidity and do not flow out the penetrating water.

In this paper, the numerical analyses of the tunnel lining used for maintaining the old tunnel (Fig. 2) were conducted. The tunnel lining is made from FRP corrugate sheet not only to support the lining concrete in the tunnel but also to flow the water or/and the moisture swept on the tunnel surface.

The FRP corrugate sheet is supported by the anchor bolts fixed on the rock. In numerical analyses, the finite element degenerate shell is adopted to represent the FRP behavior. The proposed FRP corrugate sheet is adopted and the distributed load equivalent to the 


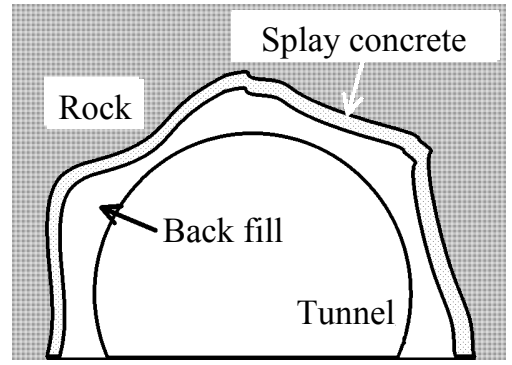

Fig. 1 Tunnel section.

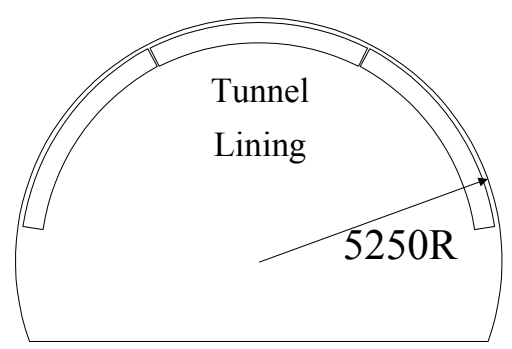

Fig. 2 Cross section of tunnel.

concrete peeled from the tunnel lining is applied and the stresses of the FRP corrugate sheet, the tensile force of bolts and the deflection of FRP corrugate sheet are investigated.

\section{Numerical Method}

2.1 FRP Corrugate Sheet Models and the Design Load

Fig. 2 shows the tunnel cross section. The radius is $5,250 \mathrm{~mm}$. In this example, three FRP corrugate sheets are placed inside the tunnel. Two types of FRP corrugate sheets are proposed. One is the FRP corrugate sheet with four drains with equal pitch $225 \mathrm{~mm}$. This sheet has been used for a tunnel lining to flow out the surface water. The drain shows a half circle of $50 \mathrm{~mm}$ in radius (Fig. 3a). The thickness is $3.3 \mathrm{~mm}$. The other is the same FRP corrugate sheet. But the FRP strip plates with $40 \mathrm{~mm}$ width by $3.3 \mathrm{~mm}$ in thickness are patched on each plateau of FRP corrugate sheet (Fig. 3b) to prevent the punching failure of the FRP corrugate sheet [4].

In-situ hole in anchor bolts is placed on a tunnel lining. The anchor bolts connect between FRP corrugate sheet and the rock behind the concrete liner. Totally, five bolts are placed in transverse direction.
In longitudinal direction, these bolts are placed in every $400 \mathrm{~mm}$ distance from center to center. Therefore, totally 25 bolts are used (Fig. 4).

The material properties were obtained from the tensile tests of FRP sheet. Fig. 5 shows the stress strain relation and the material properties are shown in Table 1.

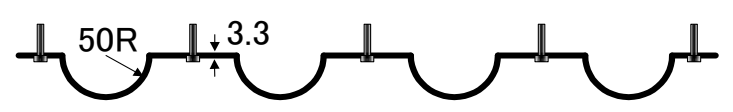

(a)

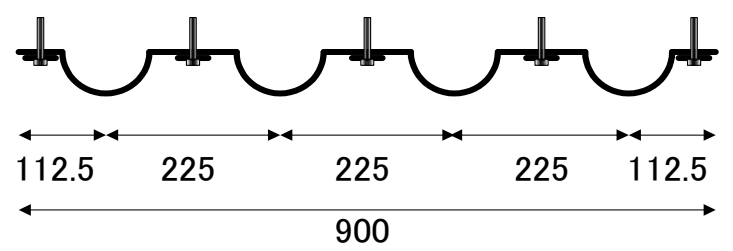

(b)

Fig. 3 Proposed cross section of FRP corrugate sheets: (a) corrugate sheet (Panel A); (b) corrugate sheet with strips (Panel B) (units in mm).

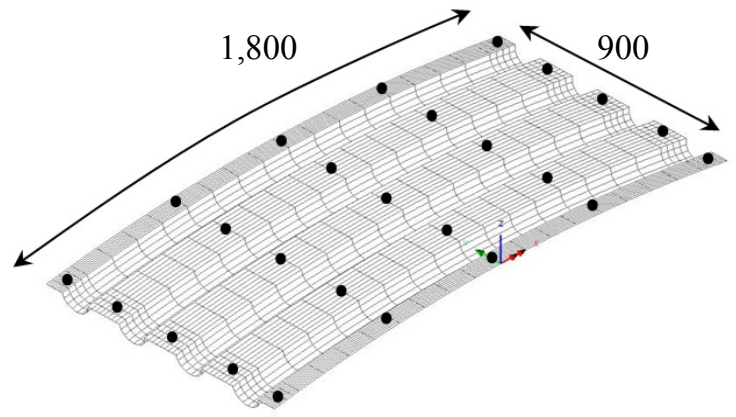

Fig. 4 Dimensions of FRP corrugate sheet ( $\mathrm{mm})$.

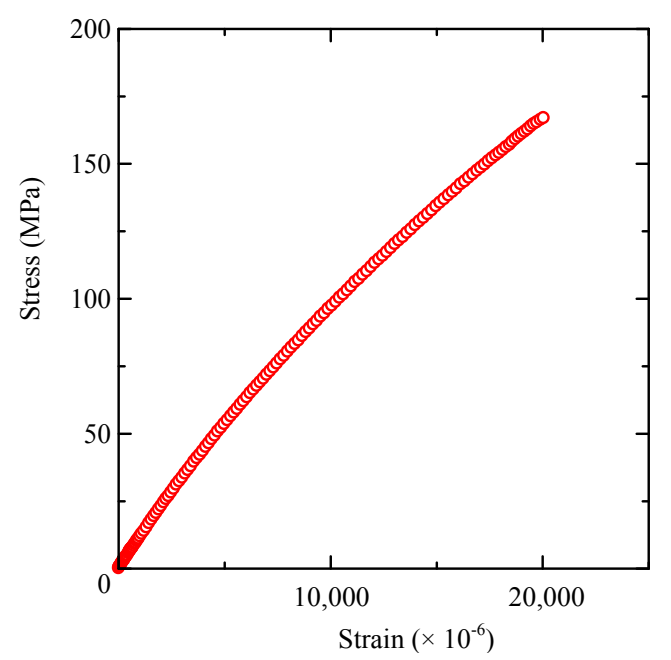

Fig. 5 Stress strain relationship of FRP. 
Table 1 Material properties.

\begin{tabular}{ll}
\hline Properties & Value \\
\hline Tensile strength & $150 \mathrm{MPa}$ \\
Elastic modulus & $10.8 \mathrm{GPa}$ \\
\hline
\end{tabular}

The assumed design load is the uniformly distribute load equivalent to $300 \mathrm{~mm}$ concrete cover. Loading is applied only to the plateaus of the cross section shown in Fig. 4 because the portion of the curved drain is not contacted to the lining concrete.

\subsection{FEM Procedure}

In numerical analyses, finite element procedure based on the isoparametric degenerate shell representation is adopted [5-7]. To simulate the nonlinear behavior, Green-Lagrange strain definition is adopted to represent the geometric nonlinearities and the elastic-plastic stress definitions are adopted considering material nonlinearities. To represent the stress distribution of the shell through the thickness, the layered approach is adopted. The shell is divided into 10 layers.

Displacement incremental scheme is adopted in the calculation of nonlinear equation to avoid the numerical instability $[7,8]$.

In the FEM model, the FRP corrugate sheet is divided into 72 elements in transverse direction and into 24 elements in longitudinal direction, respectively (Fig. 4). Each element is isoparametric eight node quadratic elements.

\section{Numerical Results and Discussion}

\subsection{Numerical Results of FRP Corrugate Sheet under Uniformly Distribute Load}

To investigate the performance of the FRP corrugate sheet, the corrugate sheets with and without stiffening strips as shown in Figs. $3 a$ and $3 b$ is analyzed. The corrugate sheet is supported at 25 points shown in Fig. 4. The uniformly distributed load is applied gradually until the flexural tensile stress in the FRP corrugate sheet exceeds its tensile strength shown in Table 1. The load-deflection relations at the center of the panel are shown in Fig.6. $\alpha$ is the magnification factor of the design load. The stiffness of Panel B (Fig. 3b) is larger than that of Panel A (Fig. 3a). Panel B represents 2.5 times ultimate strength of Panel A as well.

Table 2 shows the maximum stress and displacement in two panels under design load. Stresses in both panels are small and show the better performance. However, the maximum displacement in Panel A is not small. The stiffening strip in Panel B works well to prevent the deformation.

Table 3 shows the maximum displacement under ultimate load and the maximum tensile force arising in the anchor bolt.

Fig. 7 shows the equivalent stress distribution of Panels A and B under ultimate states. The stiffened strip redistributed the stresses arisen from the reaction of fixed bolts to the entire of the corrugated FRP sheet.

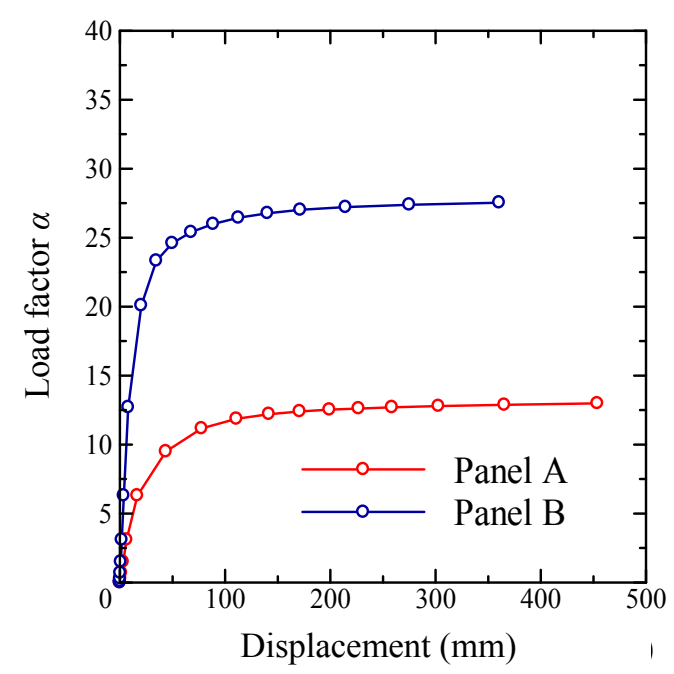

Fig. 6 Load deflection behavior.

Table 2 Stress and deformation under design load.

\begin{tabular}{lll}
\hline Type & Max. stress $(\mathrm{MPa})$ & Max. displacement $(\mathrm{mm})$ \\
\hline Panel A & 5.18 & 2.81 \\
Panel B & 3.49 & 1.01 \\
\hline
\end{tabular}

Table 3 Stress and deformation under ultimate load.

\begin{tabular}{llll}
\hline Type & $\alpha$ & $\begin{array}{l}\text { Max. displacement } \\
(\mathrm{mm})\end{array}$ & $\begin{array}{l}\text { Max. bolt tension } \\
(\mathrm{kN})\end{array}$ \\
\hline Panel A & 12.4 & 192.7 & 6.03 \\
Panel B & 26.0 & 139.8 & 13.51 \\
\hline
\end{tabular}



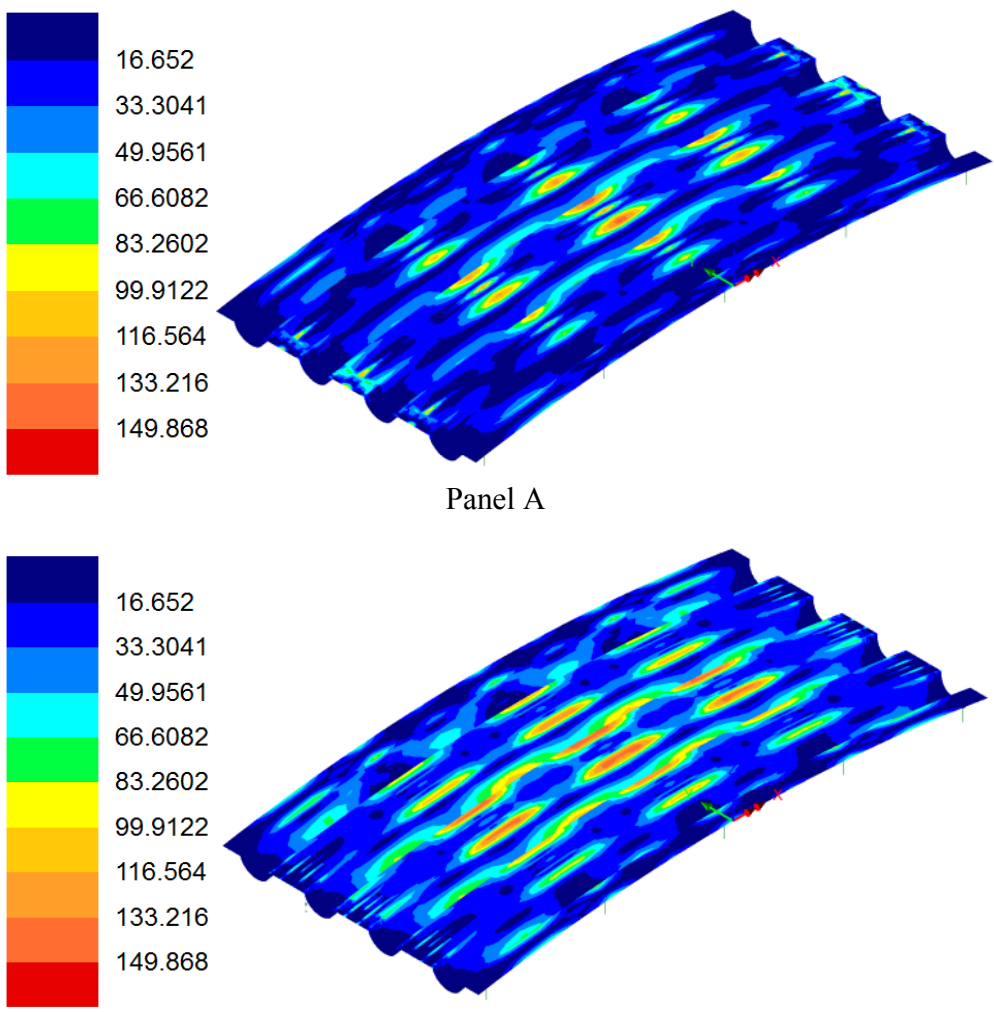

Panel B

Fig. 7 Stress distribution under ultimate load (MPa).
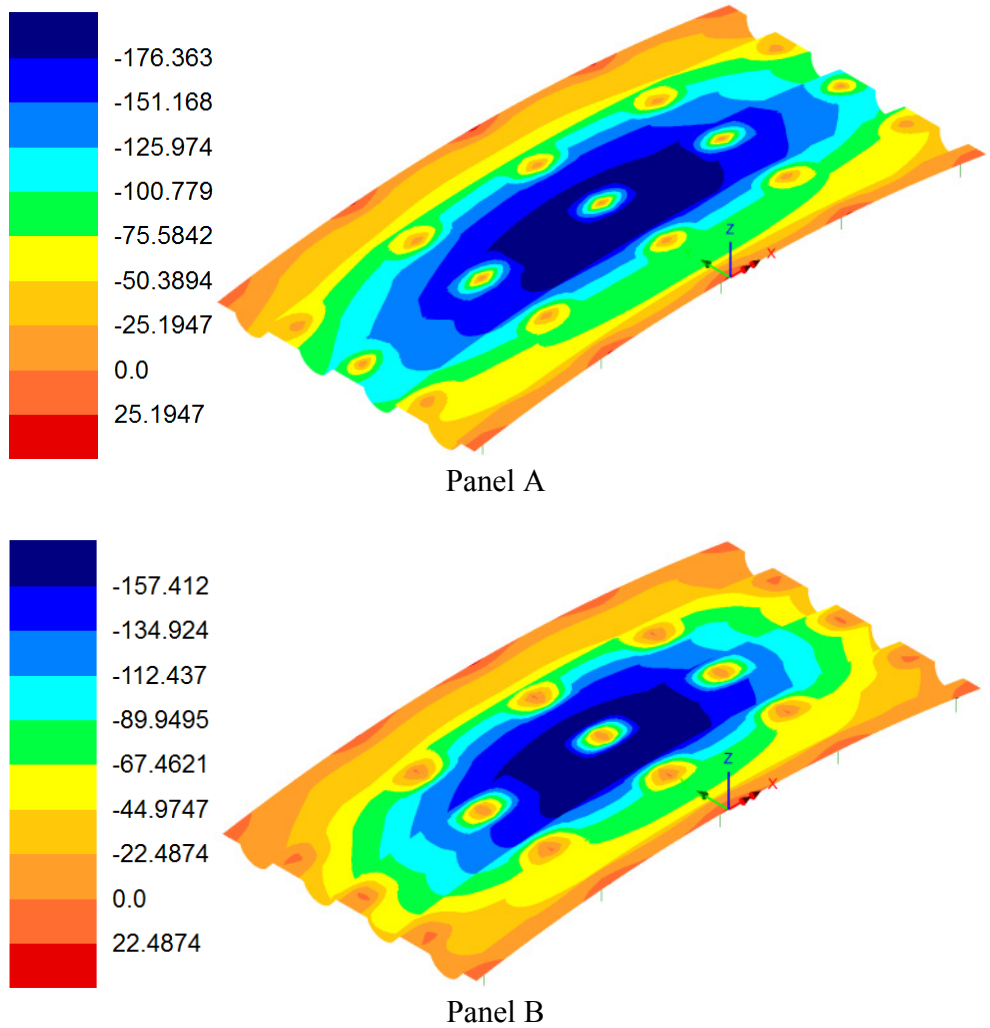

Fig. 8 Deflection distribution under ultimate load $(\mathrm{mm})$. 
Fig. 8 shows the distribution of the deflection of corrugated FRP sheet under the ultimate load. The deflection of Panel B is smaller than that of Panel A even under high ultimate load.

\subsection{Numerical Results of FRP Corrugate Sheet under} Partially Distribute Load

Confirming the efficiency of the stiffening strips on the plateau of FRP sheet, FRP corrugate sheet under partially distributed load is investigated. From the report of the accidents of concrete falling in the tunnel, the $30 \sim 80 \mathrm{~mm}$ concrete blocks fell down. Therefore, the partially distributed load shown in Fig. 9 is applied.

In numerical analyses, the effect of arranging of anchor bolts is considered. The drilling work of anchor bolts is laborious and is fairly expensive. Three patterns of anchor bolt arrangement are investigated concerning Panel B as shown in Fig. 10. In Anchor A, bolts are arranged only on the panel edges. In Anchor B, a center bolt is added to Anchor A. In Anchor $\mathrm{C}$, two bolts are subtracted from Anchor B.

Fig. 11 shows the relation between the applied load and the deflection at the center of Panel B. $\alpha$ is the magnification factor of design applied load shown in Fig. 9. Anchor A shows small stiffness and the ultimate strength.

On the other hand, Anchors B and C show the same results. Therefore, Anchor $\mathrm{C}$ is efficient as smaller numbers of bolts are arranged.

Table 4 shows the maximum stress and the maximum deflection under design load.

Table 5 shows the maximum stress and the maximum deflection under ultimate load.

Anchor C represents the better performance concerning the deflection and the tensile stress arisen in the anchor bolts.

Fig. 12 shows the equivalent stress distribution of Panel B with anchor arrangement Anchors A and C, respectively under the ultimate loading shown in
Table 5. In case of Anchor A, stress concentrates at the panel center and at the panel edges. In case of Anchor C, stresses are distributed in the panel.

Fig. 13 shows the distribution of the deflection.

Anchor $\mathrm{C}$ represents the better performance than Anchor A because the deflection in Panel B with Anchor $\mathrm{C}$ shows small differences in entire panel.

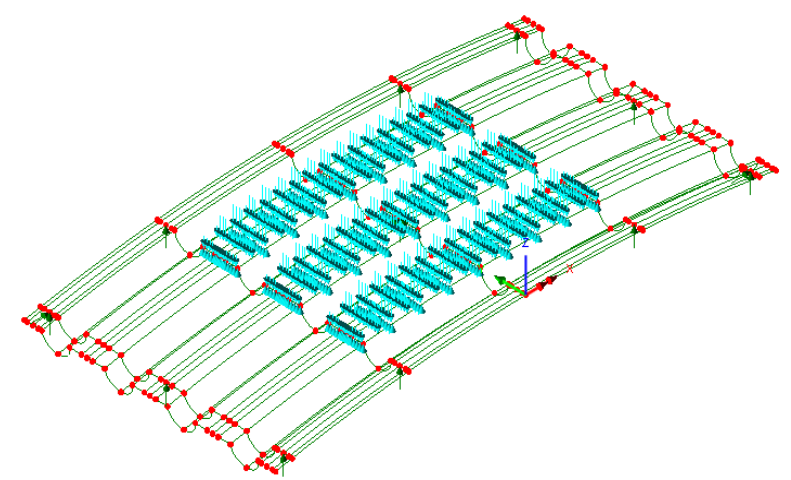

Fig. 9 Partially distributed load.

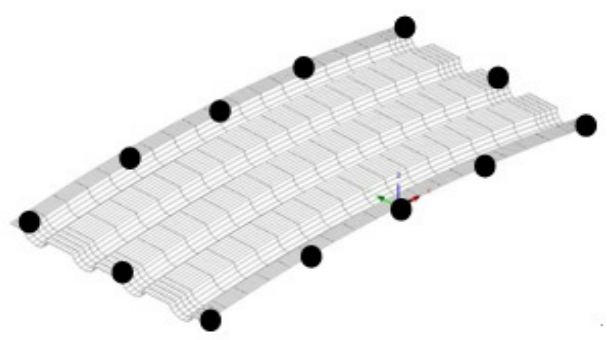

(a)

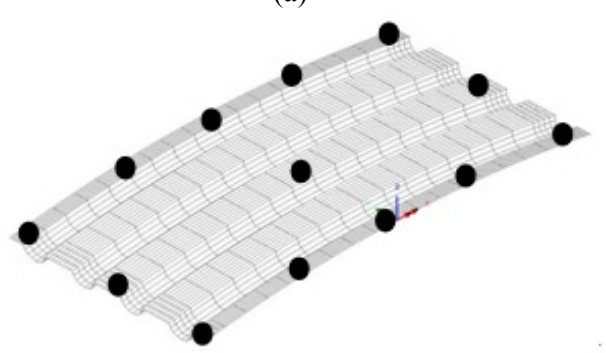

(b)

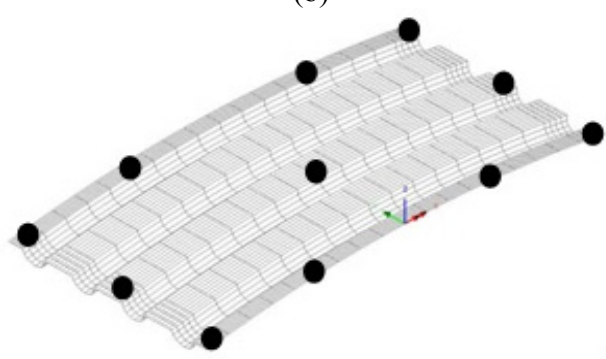

(c)

Fig. 10 Arrangement of anchor bolts: (a) Anchor A; (b) Anchor B; (c) Anchor C. 


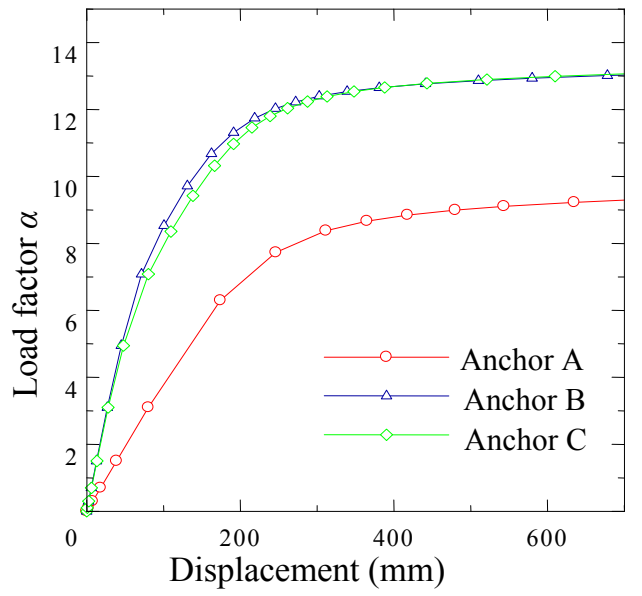

Fig. 11 Load deflection relation of Panel B with various anchor patterns.

From the numerical analyses mentioned above, Anchor $\mathrm{C}$ requires small numbers of anchors and shows the large ultimate strength and smallest deformation. Therefore, Anchor $\mathrm{C}$ shows the better performance as the corrugated FRP lining plate.

\section{Conclusions}

In this paper, FRP corrugate sheet was proposed.
The FRP corrugate sheet was supported by the anchor bolts. In numerical analyses, the finite element degenerate shell was adopted to represent the FRP sheet behavior. From the numerical analysis, the following conclusions are obtained.

FRP corrugate sheet shows better performance because the small deflection and the large rigidities to repair an old tunnel are obtained.

Stiffening strips are effective to improve the corrugate FRP sheet to prevent the punching by the anchor bolts and strengthening the rigidity.

Table 4 Stress and deflection under design load.

\begin{tabular}{lll}
\hline Anchor & Max. stress (MPa) & Max. deflection $(\mathrm{mm})$ \\
\hline Anchor A & 28.64 & 28.47 \\
Anchor B & 5.30 & 9.46 \\
Anchor C & 9.33 & 9.98 \\
\hline
\end{tabular}

Table 5 Stress and deflection under ultimate load.

\begin{tabular}{llll}
\hline Anchor & $\alpha$ & $\begin{array}{l}\text { Max. deflection } \\
(\mathrm{mm})\end{array}$ & $\begin{array}{l}\text { Max bolt tension } \\
(\mathrm{kN})\end{array}$ \\
\hline Anchor A & 7.0 & 210.4 & 8.57 \\
Anchor B & 10.7 & 217.8 & 12.13 \\
Anchor C & 10.3 & 205.3 & 12.13 \\
\hline
\end{tabular}
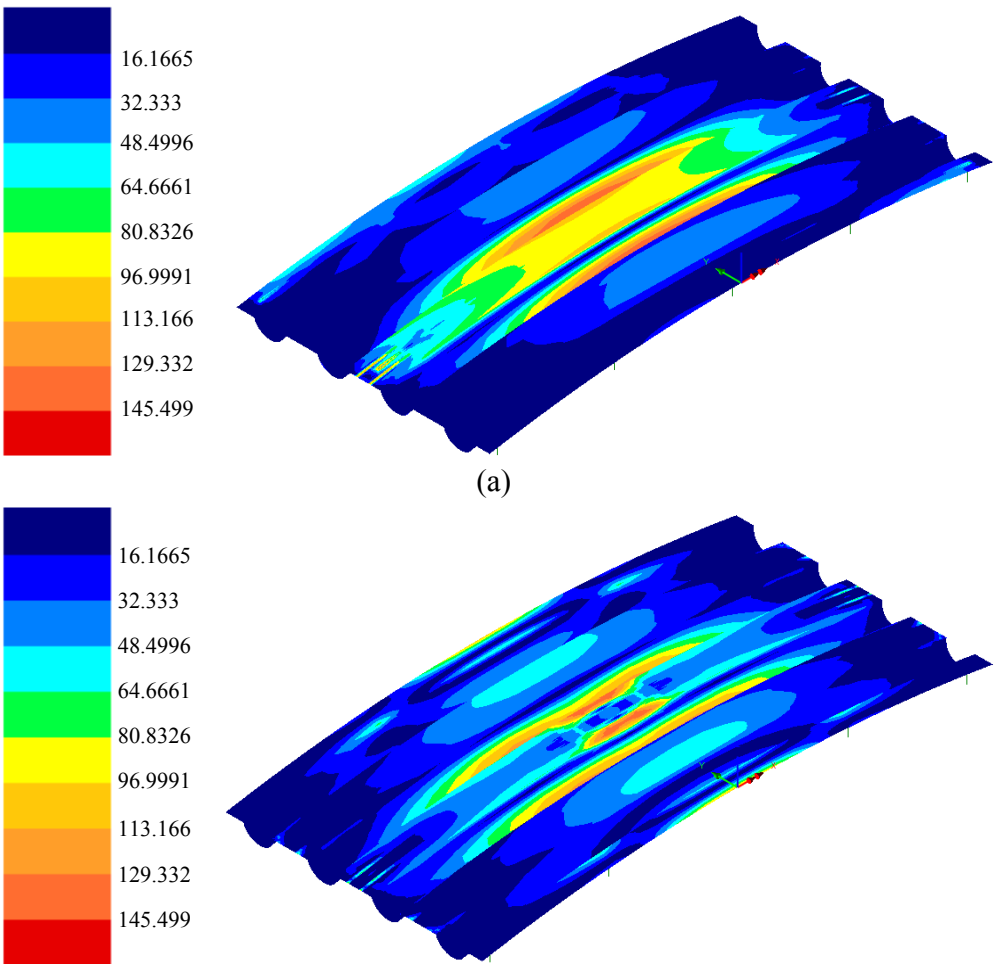

(a)

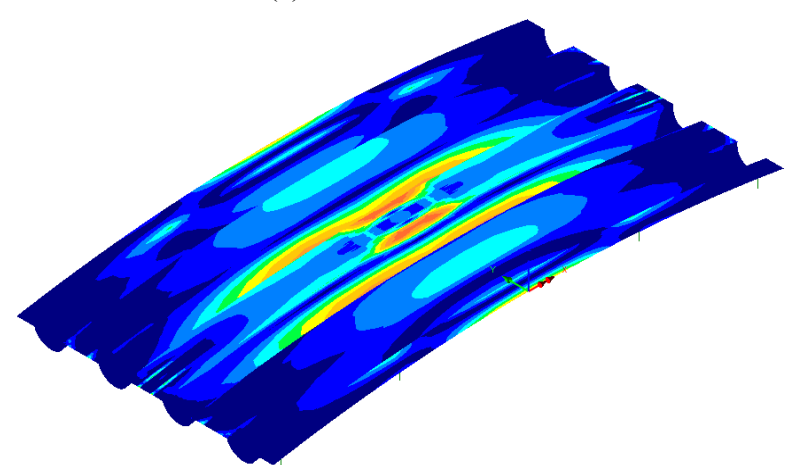

(b)

Fig. 12 Stress distribution in Panel B (MPa): (a) Anchor A; (b) Anchor C. 

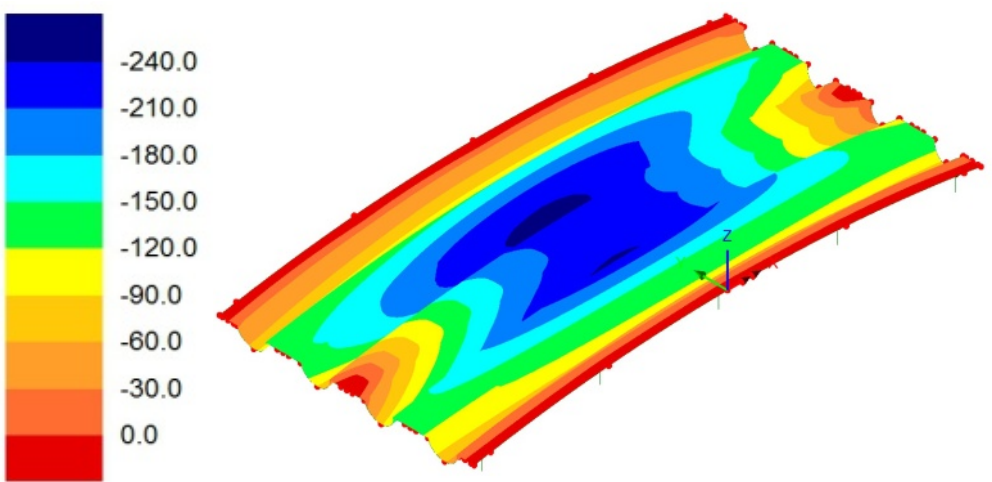

(a)
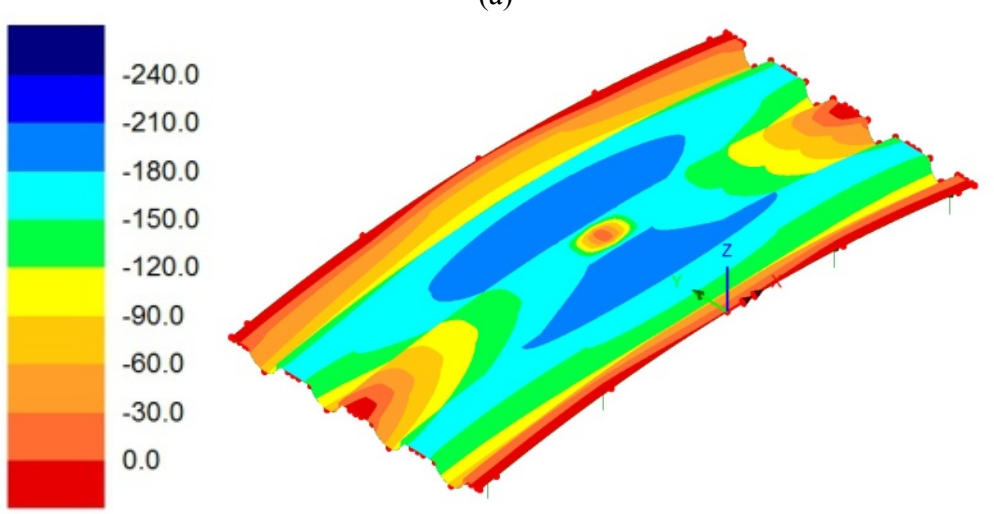

(b)

Fig. 13 Deflection of Panel B (mm): (a) Anchor A; (b) Anchor C.

Better performance and the work savings are obtained using appropriate arrangement of the anchor bolt.

As FRP corrugate sheet has a transparency, it will be possible to find new cracks and the small movement of rocks and concrete. It is easy to monitor and to maintenance the tunnel. Also, the proposed corrugate sheet will flow the water and the moisture penetrating through the concrete. In this analysis, numerical evaluation of FRP liner was presented. The practical application tests are planned both on site and laboratory.

\section{References}

[1] Okamura, H., and Ouchi, M. 2003. "Delf Compacting Concrete." Journal of Advanced Concrete Technology 1 (1): $5-15$.
[2] Asakura, T., and Kojima, Y. 2003. "Tunnel Maintenance in Japan." Tunnelling and Underground Space Technology 18: 161-9.

[3] JSCE (Japan Society of Civil Engineers). 2005. Recommendation for Concrete Repair and Surface Protection of Concrete Structure. Japan: Concrete Library 119. (in Japanese).

[4] Kaw, A. K. 1997. Mechanics of Composite Materials. UK: CRC Press.

[5] Hara, T. 2009. "Analysis and Design of FRP Dome Structure." In Proceedings of International Conference on Computational Design in Engineering, 641-4.

[6] Hinton, E., and Owen, D. R. J. 1984. Finite Element Software for Plates and Shells. Swansea: Pineridge Press

[7] Hara, T. 2014. "Structural Behavior of FRP Tunnel Lining." Advanced Material Research 831: 115-9.

[8] Hara, T. 2014. "Tunnel Lining with Corrugated FRP Sheets." In Proceedings of 2014 International Conference in Computing in Civil Engineering, 761-8. 